\title{
Conformation, structure, quadrupole coupling constants and van der Waals potential energy surface of dichloromethane-Ar
}

\author{
Biagio Velino $^{a}$, Luca Evangelisti $^{\mathrm{b}}$, Walther Caminati $^{\mathrm{b}, *}$, Rui Fausto ${ }^{\mathrm{c}}$ \\ a Dipartimento di Chimica Fisica e Inorganica dell'Università, Viale Risorgimento 4, I-40136 Bologna, Italy \\ b Dipartimento di Chimica “G. Ciamician”, Università di Bologna, Via Selmi 2, I-40126 Bologna, Italy \\ ${ }^{\mathrm{c}}$ Department of Chemistry, University of Coimbra, P-3004-535 Coimbra, Portugal
}

\section{A R T I C L E I N F O}

\section{Article history:}

Received 17 December 2009

Received in revised form 12 February 2010

Accepted 12 February 2010

Available online 10 March 2010

\section{Keywords:}

Rotational spectroscopy

Molecular complexes

Large amplitude motions

Pulsed jets

Argon

\begin{abstract}
A B S T R A C T
The rotational spectra of the ${ }^{35} \mathrm{Cl}_{2}$ and ${ }^{35} \mathrm{Cl}^{37} \mathrm{Cl}$ species of dichloromethane-argon have been investigated by molecular beam Fourier-transform microwave spectroscopy. Information on the configuration, structure and internal dynamics of the complex has been obtained, and the ${ }^{35} \mathrm{Cl}$ and ${ }^{37} \mathrm{Cl}$ quadrupole coupling constants have been determined, based on the experimental data.
\end{abstract}

(c) 2010 Elsevier B.V. All rights reserved.

\section{Introduction}

Rotational spectra of molecular adducts of rare gases with small asymmetric molecules are generally characterized by inversion splittings due to the low barriers between equivalent minima in the two-dimensional (2D) potential energy surface of angular motions $[1-10]$. This is the case, for example, of the complexes of difluoromethane $\left(\mathrm{CH}_{2} \mathrm{~F}_{2}\right)$ with all rare gas $(\mathrm{RG})$. Inversion splittings of 39.316(1), 79.19(4) and 193.740(1) $\mathrm{MHz}$ have been reported for $\mathrm{CH}_{2} \mathrm{~F}_{2}-\mathrm{Xe}$ [10], $\mathrm{CH}_{2} \mathrm{~F}_{2}-\mathrm{Kr}$ [9] and $\mathrm{CH}_{2} \mathrm{~F}_{2}-\mathrm{Ar}$ [8], respectively. For $\mathrm{CH}_{2} \mathrm{~F}_{2}-\mathrm{Ne}$ the splitting is of the order of $6 \mathrm{GHz}$, but the spectrum is not yet satisfactorily interpreted [11]. In going from difluoromethane to chlorofluoromethane $\left(\mathrm{CH}_{2} \mathrm{ClF}\right)$, that is substituting a fluorine with a chlorine atom in the $\mathrm{RG}$ partner molecule, one can observe a considerable decrease of the inversion splittings, to $0.1360(2), 0.6298(6)$ and $2.9219(5) \mathrm{MHz}$ for the most abundant isotopologues of $\mathrm{CH}_{2} \mathrm{ClF}-\mathrm{Xe}$ [12], $\mathrm{CH}_{2} \mathrm{ClF}-\mathrm{Kr}$ [13] and $\mathrm{CH}_{2} \mathrm{ClF}-\mathrm{Ar}$ [14], respectively. Again, the spectrum has not yet been satisfactorily assigned for the complex with neon, $\mathrm{CH}_{2} \mathrm{ClF}-\mathrm{Ne}$ [15].

To better understand the effects of the size and of the electronegativity of the halogen atom on the potential energy surface of the van der Waals motions, we decided to investigate the rotational spectrum of dichloromethane $\mathrm{CH}_{2} \mathrm{Cl}_{2}-\mathrm{Ar}$. For this complex, apart the possible inversion tunneling, the spectrum is expected

\footnotetext{
* Corresponding author. Tel.: +39 051 2099480; fax: +39 0512099456

E-mail address: walther.caminati@unibo.it (W. Caminati).
}

to be severely complicated by the quadrupole effects of the two $\mathrm{Cl}$ atoms, with nuclear spin quantum number $I=3 / 2$, for both ${ }^{35} \mathrm{Cl}$ and ${ }^{37} \mathrm{Cl}$ isotopes. A sketch of $\mathrm{CH}_{2} \mathrm{Cl}_{2}-\mathrm{Ar}$ is given in Fig. 1 , with the principal axis systems and the polar coordinates defining the position of $\mathrm{Ar}$ with respect to $\mathrm{CH}_{2} \mathrm{Cl}_{2}$.

\section{Experimental part}

The MB-FTMW spectrum in the $6-18.5 \mathrm{GHz}$ frequency region was measured using a COBRA-type [16] pulsed supersonic-jet Fourier-transform microwave (FT-MW) spectrometer [17] described elsewhere [7]. A mixture of $2 \% \mathrm{CH}_{2} \mathrm{Cl}_{2}$ in $\mathrm{Ar}$ was expanded from ca 3 bar to about $10^{-5}$ mbar. Each rotational line is split by Doppler effect, enhanced by the molecular beam expansion in the coaxial arrangement of the supersonic jet and resonator axes. The rest frequency is calculated as the arithmetic mean of the frequencies of the Doppler components. The estimated accuracy of frequency measurements is better than $3 \mathrm{kHz}$ and lines separated by more than $7 \mathrm{kHz}$ are resolvable.

\subsection{Plausible conformations of $\mathrm{CH}_{2} \mathrm{Cl}_{2}-\mathrm{Ar}$}

Before to search for the rotational spectrum, we ran some model calculations, in order to have a reliable starting conformation. Serving this purpose we utilized first the simple distributed polarizability model (DPM) $[18,19]$, followed by ab initio calculations in the vicinity of the DPM minima. 


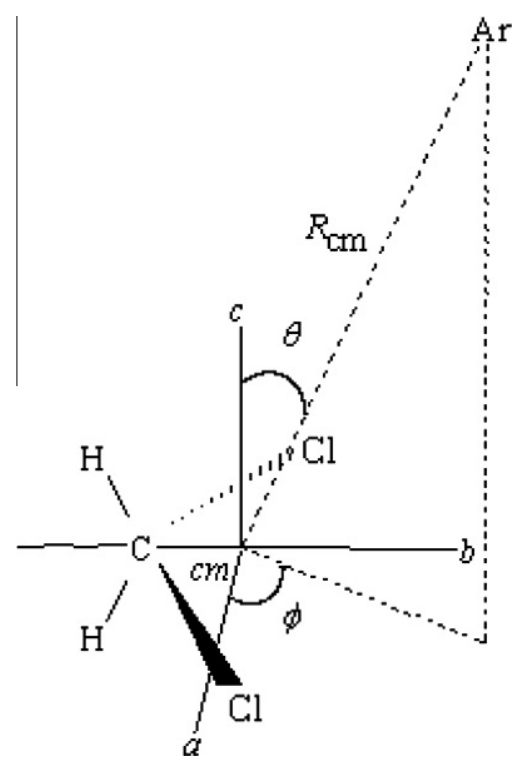

Fig. 1. Sketches of $\mathrm{CH}_{2} \mathrm{Cl}_{2}-\mathrm{Ar}$ with the polar coordinates defining the position of $\mathrm{Ar}$ with respect to $\mathrm{CH}_{2} \mathrm{Cl}_{2}$.

(a) The DPM calculations were performed using the computer program RGDMIN [20]. The geometry of $\mathrm{CH}_{2} \mathrm{Cl}_{2}$ was fixed to the experimental $r_{0}$ structure [21] while the distance $\left(R_{\mathrm{CM}}\right)$ between its center of mass $(\mathrm{CM})$ and the rare gas was free to relax for energy minimization in the full range $\theta=0-180^{\circ}, \phi=-90-270^{\circ}$ at steps of $\Delta \phi=\Delta \theta=15^{\circ} . R_{\mathrm{CM}}, \theta$ and $\phi$ are the spherical coordinates shown in Fig. 1. The obtained two-dimensional (2D) potential energy surface is shown in Fig. 2. It is qualitatively quite similar to that found for $\mathrm{CH}_{2} \mathrm{~F}_{2}-\mathrm{Ar}$ [8], with two main equivalent minima. (b) Ab initio optimizations at the MP2/6-311++G(d,p) level of theory were performed with the Gaussian03 suite of programs [22] on the found doubly degenerate minimum. These calculations were also useful to calculate the set of quadrupole coupling constants $\left(\chi_{\mathrm{hg}}, h, g=a, b, c\right)$. The ab initio calculations suggested, with respect to the DPM configuration, a considerable shift of the Ar atom towards the carbon atom. In Table 1 , we report the DPM and MP2/6$311++G(d, p)$ geometries, the calculated values for the rotational and quadrupole coupling constants, and for the $R_{\mathrm{cm}}$ and $\theta$ structural parameters ( $\phi$ is $90^{\circ}$ in both cases). In the case of the DPM configuration, the quadrupole coupling constants have been calculated at the MP2/6-311++G(d, p) level, but keeping the geometry fixed at the DPM value.

\subsection{Rotational spectrum}

The search of the spectrum was based on the rotational constants calculated for the geometries obtained with both theoretical approaches and using the quadrupole coupling constants provided in Table 1. We assigned first the set of $\mu_{\mathrm{c}}$-type transitions $(J+1)_{1, \mathrm{~J}}-$ $J_{0,}$, with $J$ in the range from 2 to 4 . Their frequencies were much closer to the values calculated with the DPM model. All of them showed a complex hyperfine structure as, for example, that of the $4_{13}-3_{03}$ transition in Fig. 3 . Then, many more $\mu_{\mathrm{c}}$-type transitions have been measured, for a total of 144 component lines. None of them displayed a tunneling splitting.

All measured line frequencies are reported as Supporting Information. These frequencies have been fitted with a Pickett SPFIT computer program [23], according to the Hamiltonian:

$\mathbf{H}=\mathbf{H}_{\mathrm{R}}+\mathbf{H}_{\mathrm{CD}}+\mathbf{H}_{Q}$

where $\mathbf{H}_{\mathrm{R}}, \mathbf{H}_{\mathrm{CD}}$ and $\mathbf{H}_{\mathrm{Q}}$ are the rotational, centrifugal distortion and quadrupolar interaction contributions, respectively.

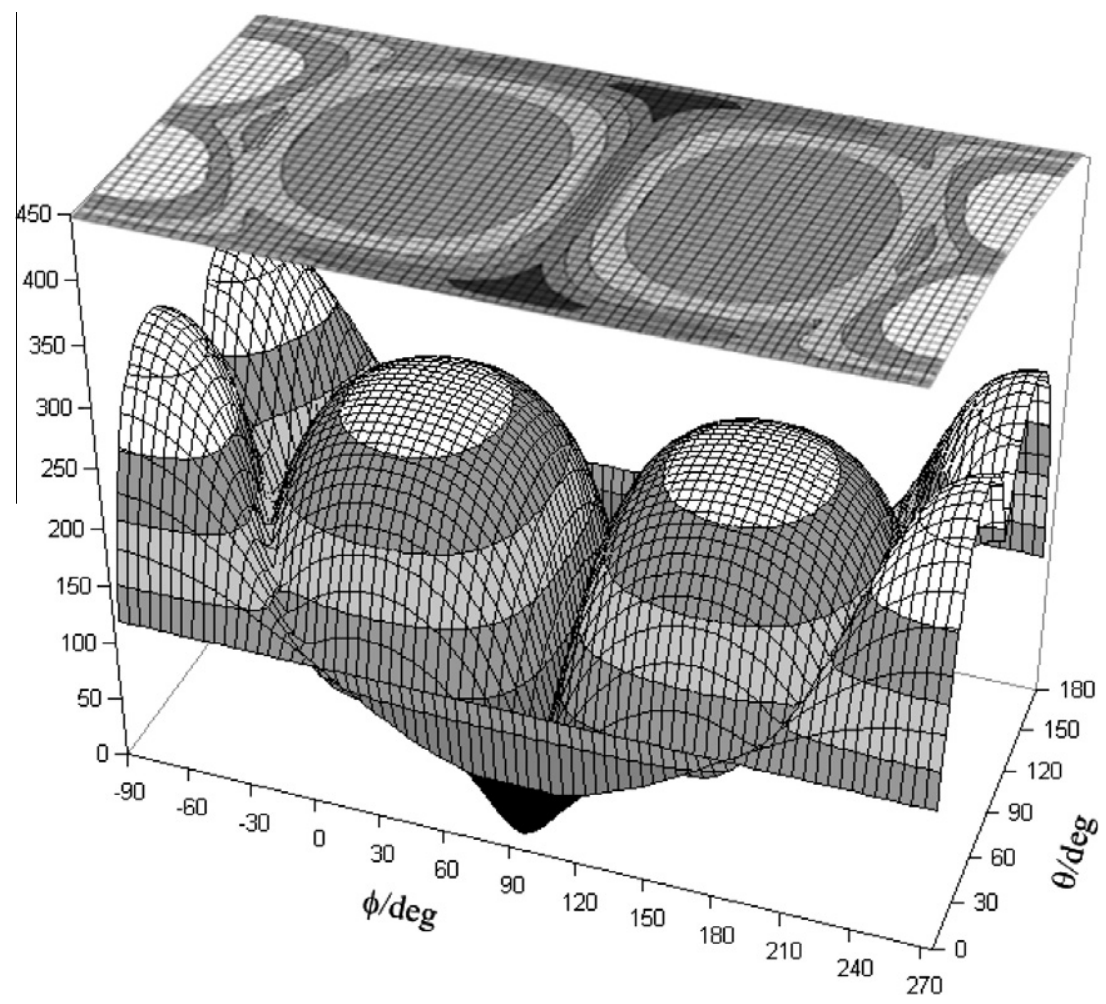

Fig. 2. Distributed polarizability model calculations: two- and three-dimensional potential energy surface as a function of the spherical coordinates $\theta$ and $\phi$. 
Table 1

MP2/6-311++G(d, p) and DPM shapes and spectroscopic parameters of $\mathrm{CH}_{2}{ }^{35} \mathrm{Cl}_{2}-\mathrm{Ar}$.

\begin{tabular}{|c|c|c|}
\hline & MP2/6-311++G(d, p) & DPM \\
\hline$A(\mathrm{MHz})$ & 3055.4 & 3073.5 \\
\hline$B(\mathrm{MHz})$ & 1207.8 & 1420.8 \\
\hline$C(\mathrm{MHz})$ & 907.7 & 1026.2 \\
\hline$\mu_{\mathrm{a}}(\mathrm{D})^{\mathrm{a}}$ & 0.3 & 0.4 \\
\hline$\mu_{\mathrm{c}}(\mathrm{D})$ & -1.7 & -1.7 \\
\hline$\chi_{\text {aa }}(\mathrm{MHz})$ & 36.8 & 36.6 \\
\hline$\chi_{\mathrm{bb}}(\mathrm{MHz})$ & -40.8 & -40.0 \\
\hline$\chi_{\mathrm{cc}}(\mathrm{MHz})$ & 4.0 & 3.5 \\
\hline$\chi_{\mathrm{ab}}(\mathrm{MHz})$ & 10.6 & 11.8 \\
\hline$\chi_{\mathrm{bc}}(\mathrm{MHz})$ & -48.3 & -48.3 \\
\hline$\chi_{\mathrm{ac}}(\mathrm{MHz})$ & 7.4 & 8.4 \\
\hline$R_{\mathrm{cm}}(\AA)$ & 3.892 & 3.543 \\
\hline$\theta(\mathrm{deg})$ & $-2.2^{\mathrm{b}}$ & 10.2 \\
\hline
\end{tabular}

a $\mu_{\mathrm{b}}=0$ by symmetry.

b Actually, within the polar coordinates, the exact ab initio values are $\theta=2.2^{\circ}, \phi=-90^{\circ}$ (in the DPM case, $\phi=90^{\circ}$ ).

Since $\mathrm{CH}_{2} \mathrm{Cl}_{2}-\mathrm{Ar}$ is a prolate near-symmetric top, the $S$-reduction and the $I^{\mathrm{r}}$-representation have been chosen [24]. The obtained spectroscopic constants are given in Table 2.

It has then been possible to assign the rotational spectrum of the $\mathrm{CH}_{2}{ }^{35} \mathrm{Cl}^{37} \mathrm{Cl}-\mathrm{Ar}$ isotopologue, which intensity is expected to be $\sim 2 / 3$ of that of the most abundant $\left(\mathrm{CH}_{2}{ }^{35} \mathrm{Cl}^{35} \mathrm{Cl}-\mathrm{Ar}\right)$ species. The analysis of the measured lines (experimental frequencies available as Supplementary material) has been performed as for the first isotopologue, and the obtained parameters are also reported in Table 2. Several centrifugal distortion parameters have been required to fit the spectra, according to the high floppiness of the complex.

\subsection{Structure}

In going from $\mathrm{CH}_{2} \mathrm{Cl}_{2}$ to $\mathrm{CH}_{2} \mathrm{Cl}_{2}-\mathrm{Ar}$ one can think to a hypothetical substitution of an atom of zero mass with an argon atom; it is then possible to obtain the $r_{\mathrm{s}}$ coordinates [25] of the argon atom in the principal axes system of $\mathrm{CH}_{2} \mathrm{Cl}_{2}$. At the same time, the $r_{\mathrm{s}}$ coordinates of the $\mathrm{Cl}$ atoms can be obtained in the principal axes

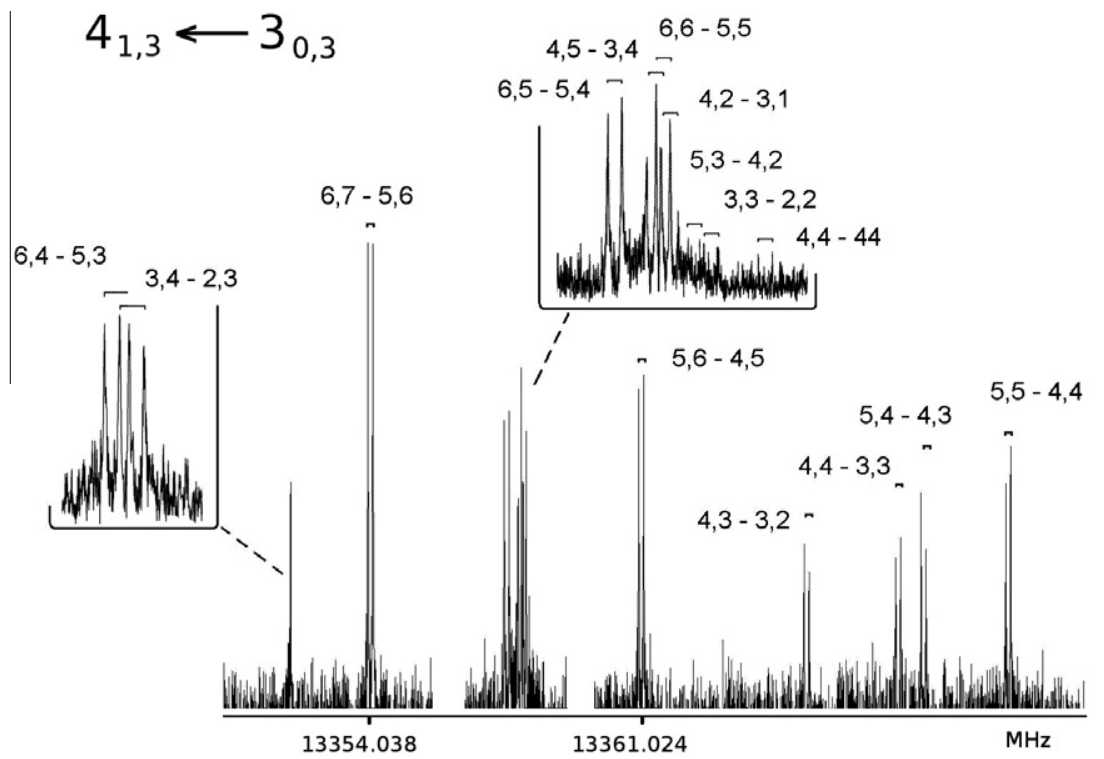

Fig. 3. Portion of the spectrum with 15 quadrupole coupling component lines of the $4_{13}-3_{03}$ transition of $\mathrm{CH}_{2}{ }^{35} \mathrm{Cl}_{2}-\mathrm{Ar}$ 
Table 2

Spectroscopic constants of $\mathrm{CH}_{2} \mathrm{Cl}_{2}-\mathrm{Ar}$ (S-reduction, $I^{\mathrm{T}}$-representation).

\begin{tabular}{lll}
\hline & $\mathrm{CH}_{2}{ }^{35} \mathrm{Cl}_{2}-\mathrm{Ar}$ & $\mathrm{CH}_{2}{ }^{35} \mathrm{Cl}^{37} \mathrm{Cl}-\mathrm{Ar}$ \\
\hline$A(\mathrm{MHz})$ & $3087.718(5)^{\mathrm{a}}$ & $3009.662(5)$ \\
$B(\mathrm{MHz})$ & $1372.6633(7)$ & $1362.9876(8)$ \\
$C(\mathrm{MHz})$ & $998.233(2)$ & $985.127(5)$ \\
$D_{\mathrm{J}}(\mathrm{kHz})$ & $24.26(3)$ & $25.63(7)$ \\
$D_{\mathrm{JK}}(\mathrm{kHz})$ & $-108.6(3)$ & $-123.1(5)$ \\
$D_{\mathrm{K}}(\mathrm{kHz})$ & $-618(1)$ & $-671(1)$ \\
$d_{2}(\mathrm{kHz})$ & $2.05(2)$ & $2.26(6)$ \\
$H_{\mathrm{JK}}(\mathrm{kHz})$ & $3.782(8)$ & $4.16(1)$ \\
$H_{\mathrm{KJ}}(\mathrm{kHz})$ & $-44.77(8)$ & $-48.96(9)$ \\
$h_{2}(\mathrm{~Hz})$ & $63.9(5)$ & $75(2)$ \\
$\chi_{\mathrm{aa}}\left({ }^{35} \mathrm{Cl}\right)(\mathrm{MHz})$ & $38.902(2)$ & $38.814(5)$ \\
$\left(\chi_{\mathrm{bb}}-\chi \mathrm{cc}\right)\left({ }^{35} \mathrm{Cl}\right)(\mathrm{MHz})$ & $-44.021(2)$ & $-43.170(5)$ \\
$\chi_{\mathrm{ab}}\left({ }^{35} \mathrm{Cl}\right)(\mathrm{MHz})$ & $2.7(4)$ & $4.0(3)$ \\
$\left.\chi_{\mathrm{bc}}{ }^{35} \mathrm{Cl}\right)(\mathrm{MHz})$ & $50.86(3)$ & $-50.8(2)$ \\
$\chi_{\mathrm{ac}}\left({ }^{35} \mathrm{Cl}\right)(\mathrm{MHz})$ & $0.1(10)$ & $2.1(3)$ \\
$\chi_{\mathrm{aa}}\left({ }^{37} \mathrm{Cl}\right)(\mathrm{MHz})$ & - & $30.715(6)$ \\
$\left(\chi_{\mathrm{bb}}-\chi \mathrm{cc}\right)\left({ }^{37} \mathrm{Cl}\right)(\mathrm{MHz})$ & - & $-35.327(6)$ \\
$\left.\chi_{\mathrm{ab}}{ }^{37} \mathrm{Cl}\right)(\mathrm{MHz})$ & - & $-1.0(3)$ \\
$\chi_{\mathrm{bc}}\left({ }^{37} \mathrm{Cl}\right)(\mathrm{MHz})$ & - & $-40.1(2)$ \\
$\chi_{\mathrm{ac}}\left({ }^{37} \mathrm{Cl}\right)(\mathrm{MHz})$ & - & $2.3(3)$ \\
$\sigma(\mathrm{kHz})$ & 3.2 & 2.6 \\
$N^{\mathrm{b}}$ & 144 & 104 \\
\hline
\end{tabular}

a Error in parentheses are expressed in units of the last digits.

b Number of lines in the fit.

system of $\mathrm{CH}_{2} \mathrm{Cl}_{2}-\mathrm{Ar}$ when substituting ${ }^{35} \mathrm{Cl}$ with ${ }^{37} \mathrm{Cl}$. The two sets of data are shown in Table 3. The set of coordinates of the Ar atom is scarcely precise, because there is a dramatic change in the set of vibrational coordinates in going from $\mathrm{CH}_{2} \mathrm{Cl}_{2}$ to $\mathrm{CH}_{2} \mathrm{Cl}_{2}-\mathrm{Ar}$. For example, the value of $|a|$ of the $\mathrm{Ar}$ atom, although much larger than its uncertainty, is less reliable than it appears (it should be 0 ), because of the Coriolis effects of large amplitude van der Waals vibrations being present in the dimer, but not in the monomer. Vice versa, the set of coordinates of the $\mathrm{Cl}$ atoms in the principal axes system of $\mathrm{CH}_{2} \mathrm{Cl}_{2}-\mathrm{Ar}$ is expected to be quite reliable, because the vibrational motions are quite similar in $\mathrm{CH}_{2}{ }^{35} \mathrm{Cl}_{2}-\mathrm{Ar}$ and $\mathrm{CH}_{2}{ }^{35} \mathrm{Cl}^{37} \mathrm{Cl}$-Ar. A partial $r_{0}$ structure was obtained by fitting the distance $R_{\mathrm{cm}}$ and the angle $\theta$ of Fig. 1 to the six available rotational constants, while keeping the geometry of $\mathrm{CH}_{2} \mathrm{Cl}_{2}$ fixed to that of the isolated molecule [21]. These parameters are reported in Table 4 and there compared to the corresponding $r_{\mathrm{s}}, r_{\mathrm{DPM}}$ and $r_{\mathrm{ab}}$ initio values. The $\mathrm{Ar}$ and $\mathrm{Cl} r$ coordinates calculated with the $r_{0}$ parameters give a much better agreement for the $\mathrm{Cl}$ atoms, according with the above discussion. The $r_{0}$ structure of the complex is shown in Fig. 4. It agrees much better with the DPM rather then with the ab initio configuration.

Table 3

$r_{\mathrm{s}}$ Coordinates of $\mathrm{Ar}$ and $\mathrm{Cl}$ in the principal axis systems of $\mathrm{CH}_{2} \mathrm{Cl}_{2}$ and $\mathrm{CH}_{2} \mathrm{Cl}_{2}-\mathrm{Ar}$, respectively.

\begin{tabular}{|c|c|c|c|c|}
\hline & \multicolumn{2}{|l|}{$\mathrm{Ar}$} & \multicolumn{2}{|l|}{$\mathrm{Cl}$} \\
\hline & Exp. & Calc. $^{a}$ & Exp. & Calc. $^{a}$ \\
\hline$|a|(\AA)$ & $0.127(1)$ & 0.000 & $1.117(2)$ & 1.116 \\
\hline$|b|(\AA)$ & $1.290(2)$ & 0.995 & $1.467(2)$ & 1.467 \\
\hline$|c|(\AA)$ & $3.375(1)$ & 3.469 & $0.20(2)$ & 0.184 \\
\hline
\end{tabular}

${ }^{\text {a }}$ From the $r_{0}$ structure of Table 4 .

Table 4

$r_{\mathrm{s}}$ and $r_{0}$ and $r_{\mathrm{DPM}}$ structural van der Waals parameters (see text and Fig. 1).

\begin{tabular}{lllcr}
\hline & $r_{\mathrm{s}}$ & $r_{0}$ & $r_{\mathrm{DPM}}$ & $r_{\mathrm{ab}}$ initio \\
\hline$R_{\mathrm{cm}}(\AA)$ & 3.611 & $3.608(1)$ & 3.543 & 3.892 \\
$\theta(\mathrm{deg})$ & 20.9 & $16(5)$ & 10.2 & $-2.2^{\mathrm{a}}$ \\
\hline
\end{tabular}

a Actually, within the polar coordinates, the correct value is $\theta=2.2^{\circ}, \phi=-90^{\circ}$ (in all other cases, $\phi=90^{\circ}$ ).

\section{4. van der Waals vibrations}

The motions of the rare gas atom (RG) in a molecular complex are generally described by a radial part, the stretching of RG with respect to the center of mass of the partner molecule, and an angular part, which can be thought of as two bending motions of the $\mathrm{Ar}$ atom in the complex described by $\theta$ and $\phi$ (Fig. 1). We will discuss below the limitations encountered to determine the potential energy surface of these motions in the case of $\mathrm{CH}_{2} \mathrm{Cl}_{2}-\mathrm{Ar}$.

\subsubsection{Van der Waals stretching and dissociation energy}

For asymmetric top complexes, in which the stretching coordinate is near-parallel to the inertial $a$-axis, the stretching force constant and then the dissociation energy can be calculated from the $D_{\text {J }}$ centrifugal distortion constant within the pseudo diatomic approximation [26]. For example, reliable and consistent results have been obtained within the $\mathrm{CH}_{2} \mathrm{~F}_{2}-\mathrm{RG}$ family, with $\mathrm{RG}=\mathrm{Ar}$, $\mathrm{Kr}$, Xe [10]. However, in the case of $\mathrm{CH}_{2} \mathrm{Cl}_{2}-\mathrm{Ar}$ the values of $D_{\mathrm{J}}$ and of the reduced mass of the motion are so high that they would bring to a very low dissociation energy, $E_{\mathrm{B}} \approx 0.5 \mathrm{~kJ} \mathrm{~mol}^{-1}$. We feel this value to be too low, when compared to the ab initio value $E_{\mathrm{B}, \mathrm{DPM}} \approx 5 \mathrm{~kJ} \mathrm{~mol}^{-1}$, or, for example, to $E_{\mathrm{B}}\left(\mathrm{CH}_{2} \mathrm{~F}_{2}-\mathrm{Ar}\right) \approx 1.5 \mathrm{~kJ} \mathrm{~mol}^{-1}$ [8]. The failure could be due to a coupling of the van der Waals stretching with the van der Waals angular motions, or to a correlation of $D_{\mathrm{J}}$ with another centrifugal distortion parameter not needed - apparently - in the fit.

\subsubsection{Tunneling motion}

In the previously investigated complexes of $\mathrm{CH}_{2} \mathrm{~F}_{2}$ and $\mathrm{CH}_{2} \mathrm{FCl}$ with rare gases, $\mu_{\mathrm{c}}$-type transitions always displayed tunneling splittings. Assuming a pathways for the tunneling motion, it was possible to determine the corresponding $B_{2}$ inversion barrier. In the case of $\mathrm{CH}_{2} \mathrm{Cl}_{2}-\mathrm{Ar}$, no tunneling splittings have been observed, so that it is only possible to give a lower limit for the $B_{2}$ barrier to inversion. Assuming the same pathways and structural relaxation as for $\mathrm{CH}_{2} \mathrm{~F}_{2}-\mathrm{Ar}$ [8] - confirmed by the DPM model - , this lower limit has been calculated with Meyers's one-dimensional flexible model [27], and the result is shown in Table 5, where the corresponding values are given also for the related complexes, $\mathrm{CH}_{2} \mathrm{~F}_{2}-$ $\mathrm{Ar}$ and $\mathrm{CH}_{2} \mathrm{FCl}-\mathrm{Ar}$. It seems that the $\mathrm{Cl}$ atoms produce a repulsion,

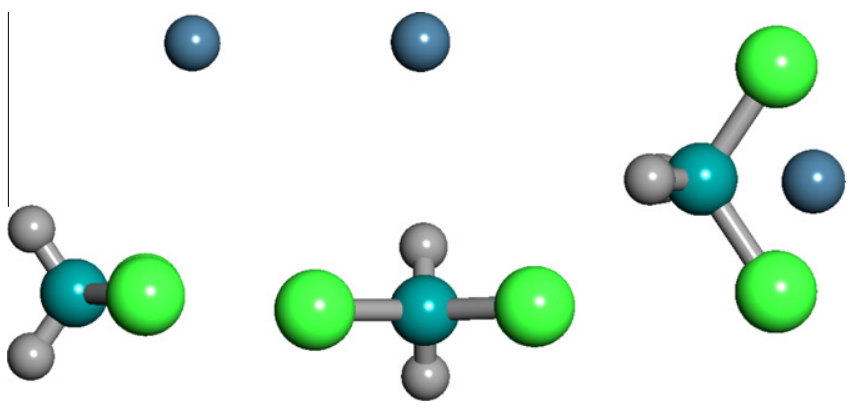

Fig. 4. The configuration of the complex, according to the DPM model and to the experimental structure, as view along the directions of the $a, b$, and $c$ principal axes of $\mathrm{CH}_{2} \mathrm{Cl}_{2}$.

Table 5

Inversion splittings $(\Delta E)$ and inversion barriers $\left(B_{2}\right)$ of the most abundant isotopologues in the family $\mathrm{CH}_{2} \mathrm{~F}_{2}-\mathrm{Ar}, \mathrm{CH}_{2} \mathrm{FCl}-\mathrm{Ar}$ and $\mathrm{CH}_{2} \mathrm{Cl}_{2}-\mathrm{Ar}$.

\begin{tabular}{llll}
\hline & $\mathrm{CH}_{2} \mathrm{~F}_{2}-\mathrm{Ar}$ & $\mathrm{CH}_{2} \mathrm{FCl}-\mathrm{Ar}$ & $\mathrm{CH}_{2} \mathrm{Cl}_{2}-\mathrm{Ar}$ \\
\hline$\Delta E(\mathrm{MHz})$ & $193.740(1)$ & $2.9219(5)$ & $<0.004$ \\
$B_{2}\left(\mathrm{~kJ} \mathrm{~mol}^{-1}\right)$ & 1.1 & 0.73 & $>1.5$ \\
Refs. & {$[8]$} & {$[14]$} & This work \\
\hline
\end{tabular}


when compared to the $\mathrm{F}$ atoms, on $\mathrm{Ar}$. This correspond to a lower $\theta$ value, and then to a larger tunneling motion (or wider tunneling barrier). In addition, a larger reduced mass contributes to produce smaller inversion splittings than those measured for the related complexes.

\section{Conclusions}

The configuration of $\mathrm{CH}_{2} \mathrm{Cl}_{2}-\mathrm{Ar}$ has been unambiguously determined from the rotational constants of the two investigated isotopologues. It agrees better with the results of a simple DPM model calculations. The relatively more sophisticated MP2/6$311++G(d, p)$ ab initio calculations suggest a different configuration of the global minimum, which has not been confirmed by the experimental evidences.

The inversion splittings decrease from the 193.740(1) $\mathrm{MHz}$ of $\mathrm{CH}_{2} \mathrm{~F}_{2}-\mathrm{Ar}$ [8], through 2.9219(5) $\mathrm{MHz}$ of $\mathrm{CH}_{2} \mathrm{FCl}-\mathrm{Ar}$ [14], to less than half of our experimental resolving power, that is to less than $4 \mathrm{kHz}$. Since the $B_{2}$ barriers are so much different from each other in the three cases, the dramatic reduction of the tunneling splitting is due to the higher reduced masses of the tunneling motions in going from $\mathrm{CH}_{2} \mathrm{~F}_{2}-\mathrm{Ar}$ to $\mathrm{CH}_{2} \mathrm{Cl}_{2}-\mathrm{Ar}$, and also to the fact that the freon counterpart plays an important role in determining the thickness of the barrier (smaller $\theta$ for $\mathrm{CH}_{2} \mathrm{Cl}_{2}-\mathrm{Ar}$ ).

The centrifugal distortion effects seems to not provide a reliable value of the dissociation energy.

\section{Acknowledgments}

We thank the University of Bologna for financial support. We also acknowledge the Italian CNR and the Portuguese FCT organisations for supporting the biennial scientific cooperation agreement 411/00 CNR.

\section{Appendix A. Supplementary material}

Supplementary data associated with this article can be found, in the online version, at doi:10.1016/j.molstruc.2010.02.040.

\section{References}

[1] I.I. Ioannu, R.L. Kuczkowski, J.T. Hougen, J. Mol. Spectrosc. 171 (1995) 265; I.I. Ioannu, R.L. Kuczkowski, J. Mol. Spectrosc. 166 (1994) 354; S. Melandri, A. Dell'Erba, P.G. Favero, W. Caminati, J. Mol. Spectrosc. 222 (2003) 121.

[2] S. Melandri, P.G. Favero, W. Caminati, B. Velino, J. Chem. Phys. 122 (2005) 134310-1-134310-7.

[3] A. Maris, W. Caminati, B. Velino, C.M. Andrews, B.J. Howard, Chem. Phys. Lett. 399 (2004) 39.

[4] A. Maris, W. Caminati, J. Chem. Phys. 118 (2003) 1649.

[5] P. Ottaviani, A. Maris, W. Caminati, Y. Tatamitani, Y. Suzuki, T. Ogata, J.L. Alonso, Chem. Phys. Lett. 361 (2002) 341.

[6] B. Velino, S. Melandri, W. Caminati, J. Phys. Chem. A 108 (2004) 4224.

[7] W. Caminati, A. Millemaggi, J.L. Alonso, A. Lesarri, J.C. Lopez, S. Mata, Chem. Phys. Lett. 392 (2004) 1.

[8] P. Ottaviani, S. Melandri, W. Caminati, J.C. López, J. Mol. Spectrosc. 239 (2006) 24 J.C. Lopez, P.G. Favero, A. Dell'Erba, W. Caminati, Chem. Phys. Lett. 316 (2000) 81.

[9] A. Maris, S. Melandri, W. Caminati, I. Rossi, Chem. Phys. Lett. 407 (2005) 192.

[10] S. Tang, L. Evangelisti, W. Caminati, J. Mol. Spectrosc. 258 (2009) 71; W. Caminati, J. Phys. Chem. A 110 (2006) 4359.

[11] W. Caminati et al., in: 16th Colloquium on High Resolution Molecular Spectroscopy, Dijon, France; 6-10 September, 1999. Inv. Lect. P2.

[12] P. Ottaviani, F.M. Pesci, L.B. Favero, B. Velino, W. Caminati, Chem. Phys. Lett 466 (2008) 122

[13] P. Ottaviani, B. Velino, W. Caminati, J. Phys. Chem. A 111 (2007) 12344.

[14] P. Ottaviani, J.-U. Grabow, W. Caminati, J. Chem. Phys. 125 (2006) 194302.

[15] W. Caminati et al., unpublished.

[16] J.-U. Grabow, W. Stahl, Z. Naturforsch A. 45 (1990) 1043; J.-U. Grabow, Doctoral Thesis, Christian-Albrechts-Universität zu Kiel, Kiel, 1992;

J.-U. Grabow, W. Stahl, H. Dreizler, Rev. Sci. Instrum. 67 (1996) 4072; <http://www.pci.uni-hannover.de/ lgpca/spectroscopy/ftmw>.

[17] T.J. Balle, W.H. Flygare, Rev. Sci. Instrum. 52 (1981) 33.

[18] Z. Kisiel, P.W. Fowler, A.C. Legon, J. Chem. Phys. 95 (1991) 2283.

[19] Z. Kisiel, J. Phys. Chem. 95 (1991) 7605.

[20] Z. Kisiel, PROSPE - Programs for Rotational SPEctroscopy, <http:// info.ifpan.edu.pl/ kisiel/prospe.htm>

[21] R. Wellington Davis, A.G. Robiette, M.C.L. Gerry, J. Mol. Spectrosc. 85 (1981) 399.

[22] M.J. Frisch et al., Gaussian03, Revision B.04; Gaussian Inc., Pittsburgh, PA, 2003.

[23] H.M. Pickett, J. Mol. Spectrosc. 148 (1991) 371; H.M. Pickett, J. Chem. Phys. 56 (1972) 1715.

[24] J.K.G. Watson, in: J.R. Durig (Ed.), Vibrational Spectra and Structure, vol. 6, Elsevier, New York/Amsterdam, 1977, pp. 1-89.

[25] J. Kraitchman, Am. J. Phys. 21 (1953) 17.

[26] S.E. Novick, S.J. Harris, K.C. Janda, W. Klemperer, Can. J. Phys. 53 (1975) 2007

[27] R. Meyer, J. Mol. Spectrosc. 76 (1979) 266. 